in this editorial. For example, the authors refer to the work of Andreason et al (1987) which purports to show an association between self-report of heavy cannabis use on conscription to the Swedish army and later admission for schizophrenia. They fail to point out, however, that Andreason et al do not indicate whether or not the subjects were taking drugs when the diagnosis of schizophrenia was made, despite the fact that they state that drugtaking in recruits is correlated with later drugtaking.

The authors state that if the individual cannot be persuaded to discontinue the use of drugs, "causation may be irrelevant". This makes no sense when both treatment and prognosis depend upon it. If the diagnosis of what the authors call "intoxication mimicking functional psychosis" (what is usually called drug-induced psychosis) were made correctly and the patient confronted with the reality that his terrifying symptoms are caused by the drug, then advice to desist from drugs might not be as ineffective as the authors seem to think. To maintain a pretence that we have a pharmacological treatment when the only treatment is abstention (with suitable help) is to remove the responsibility for abstention from the patient and to prolong the suffering. Misdiagnosis is very costly to the community services in terms of nursing, "depot clinics" and drugs; it is even more costly to the patients and it destroys the value of research.

Andreason, S., Allebeck, P., Engstrom, A., et al (1987) Cannabis and schizophrenia. A longitudinal study of Swedish conscripts. Lancet, ii, 1483-1486.

COHEN, S. I. (1995) Overdiagnosis of schizophrenia: role of alcohol and drug misuse. Lancet. 346, 1541-1542.

Pool.E. R. \& Brabbins. C. (1996) Drug induced psychosis. British Journal of Psychiatry, 168, 135-138.

SmITH. J. \& HUCKER, S. (1994) Schizophrenia and substance abuse. British Journal of Psychiatry: 165, 13-21.

S. I. COHEN

8 Linnell Drive

London NWI1 $7 L T$

\section{Public attitudes to mental illness}

SIR: Wolff et al (1996) present a welcome account of popular conceptions of mental illness. Of particular interest is the attempt to elicit the knowledge base which might underpin negative attitudes towards mental patients in the general population. Many studies have reported predominantly negative attitudes towards the mentally ill. Some (Borenstein, 1992) concur with Wolff et al, in concluding that the lay person is undereducated rather than mis-educated in psychiatric knowledge.
Irving Schneider (1987) described movie psychiatry as having developed its own characteristics, 'which only occasionally intersect with those of the real life profession.' Similarly, I would like to suggest that there are strong popular conceptions of mental illness, but these are different from the frame of reference established by psychiatrists. Testing knowledge or orthodox psychiatric concepts, such as schizophrenia or bipolar disorder, would inevitably show the public to have a lack of knowledge, but would not necessarily identify a false knowledge base. Many studies of the portrayal of mental illness in the media (Matas et al, 1985) show portrayal heavily biased towards antisocial aspects of behaviour, such as murder or senseless violence.

In a community study I carried out some years ago, I compared the views of 150 health centre attenders with those of $\mathbf{2 0}$ senior psychiatrists, as to the symptoms characterising various types of mental illness. Lay people did, indeed, 'under-diagnose' psychotic and affective disorders relative to psychiatrists. In contrast, however, antisocial behaviours were 'over-diagnosed,' as representing features of mental illness. For example, in response to the symptom 'setting fire to public buildings for no apparent reason,' over $50 \%$ of lay people yet $0 \%$ of psychiatrists felt that this symptom was definitely, or very likely, a characteristic of mental illness. Lay-person psychiatry resembled 'media psychiatry' in its over-inclusion of dangerous and unpredictable behaviour. This would explain the increased emphasis on the attitude 'Social Control'

I believe this represents something of a dilemma for public education because, on the one hand, there is an increasing emphasis on developments in forensic psychiatry, such as local secure units and Court diversion schemes, that is bound to highlight further the problems associated with the mentally disordered offender. I feel that there would be a useful role for the College's Public Education Committee, in conjunction with user groups, in mounting a 'media watch campaign' in an attempt to curb the more outrageous sensationalism in current reporting.

Borenstein, A. B. (1992) Public attitudes towards persons with mental illness. Health Affairs, 11, 186-196.

Matas, M., el Guebaly, N., Peterkin, A., et al (1985) Mental illness and the media. An assessment of attitudes and communication. Canadian Journal of Psychiatry, 30, 12-17.

SCHNEIDER, I. (1987) The theory and practice of movie psychiatry. American Journal of Psychiatry, 144, 996-1002.

Wolff, G., Pathare, S., Craig, T., et al (1996) Community attitudes to mental illness. British Journal of Psychiatry. 168 , 183-191.

Peter Hodgkinson Centre

T. J. O'GRADY 